\title{
On Angles Between Two Images
}

\author{
Agah D Garnadi ${ }^{1,2}$, Teduh Wulandari Mas'oed ${ }^{1 *}$ \\ ${ }^{2}$ Ronin Mathematician \\ Department of Mathematics \\ Faculty of Mathematics and Natural Sciences \\ IPB University \\ Email: ${ }^{1}$ agah.garnadi@mail.com, ${ }^{*, 2}$ teduhma@apps.ipb.ac.id \\ *Corresponding author \\ Dedicated to Dr Siswadi on his 71st birthday
}

\begin{abstract}
An image consisting of $(m, n)$ pixels can be seen as a matrix of $m \times n$ size. Based on the formula of angles between two subspaces, a pair of angles can be defined between two matrices, by utilizing column spaces and row spaces of the two matrices. The singular values of each matrix can be used to calculate distances. Thus, a distance representation is obtained, and a pair of angles between 2 matrices of the same size.
\end{abstract}

Keywords: Images, matrices, angles, subspace, linear algebra applications

\section{INTRODUCTION}

In text-mining, such as in search engines, the basic concept of Linear Algebra, angular, is often used to measure how close the search vector is relative to the corpus [1] [2]. Based on the basic concept of angles in linear algebra, and by using vector representations of matrices that are used to calculate angles between two matrices, the usual understanding of angles between two vectors can be used, namely by calculating the magnitude of angles formed by two vectors into a way to calculate the angles of two matrices. By utilizing the angular formula between two subspace, we also get a pair of angles between two matrices, this calculation utilizes the column space and row space of the two matrices.

$A, B \in R^{m, n}$ : Images formed from $m \times n$ pixels, as a matrix.

\section{Pair of Angles Between Two Images}

\subsection{On Angle between two subspaces}

We rely much of the result in this work on the definition of angle between two subspaces $([4],[5], 315)$.

Let $(X,<., .>)$ Is the product space in dimensions of 2 or more, $U=\operatorname{span}\left\{u_{1}, u_{2}, \cdots, u_{p}\right\}$ and $V=\operatorname{span}\left\{v_{1}, v_{2}, \cdots, v_{q}\right\}$ are 2 subspace in $X$ where $1 \leq p \leq q<\infty$. Let also $\left\{u_{1}, u_{2}, \cdots, u_{p}\right\}$ and $\left\{v_{1}, v_{2}, \cdots, v_{q}\right\}$ are orthonormal, then $\theta$ is the angle between subspace $U$ and $V$, given as follows.

$$
\cos ^{2}(\theta)=\operatorname{det}\left(M M^{T}\right)
$$

with $M:=\left[<u_{i}, v_{k}>\right]=\left[u_{i}^{T} * v_{k}\right]$ is a matrix of $p \times q$, and $M^{T}=\left[v_{k}^{T} * u_{i}\right]$. Note that, for the case $p=q$, the angular formula becomes:

$$
\cos (\theta)=|\operatorname{det}(M)|
$$




\subsection{Singular Value Decomposition [6] :}

$$
\begin{aligned}
& A=U_{A} D_{B} V_{A}^{T}, U_{A} \in R^{m, p}, D_{A} \in R^{p, p}, V_{A}^{T} \in R^{p, n}, \\
& B=U_{B} D_{B} V_{B}^{T}, U_{B} \in R^{m, q}, D_{B} \in R^{q, q}, V_{B}^{T} \in R^{q, n}
\end{aligned}
$$

with $U_{A}, U_{B}, V_{A}, V_{B}$ are orthonormal matrix, and $D_{A}, D_{B}$ are diagonal matrices.

$U_{A}, U_{B}$ in sequence are the column space base of $A$ and $B$. The same thing applies to $V_{A}, V_{B}$ which are sequentially the row space base of $A$ and $B$.

\subsection{SVD Approximation property}

Li et al.[10] pointed the following describes the best approximation properties of SVD theorem.

Theorem.[9] $M \in R^{l \times n}, d \leq \operatorname{rank}(M)$, and singular value decomposition for matrix $M$ is

$$
M=U \Sigma V^{T}=\left[U_{1}, U_{2}\right]\left[\Sigma_{1} ; \Sigma_{2}\right]\left[V_{1}, V_{2}\right]^{T},
$$

where $U_{1} \in R^{l \times d}, \Sigma_{1} \in R^{d \times d}$, and $V_{1} \in R^{n \times d}$.

If the energy of image is expressed by the square of the F-norm, one can get

$$
\|M\|_{F}^{2}=\operatorname{tr}\left(M^{T} M\right)=\operatorname{tr}\left(V \Sigma U^{T} U \Sigma V^{T}\right)=\sum_{i=1}^{r} \sigma_{i}^{2},
$$

where $\sigma_{i}$ is nonzero singular value for M. $r$ is the rank of matrix.

After the singular value decomposition, we can see from formula 4 that the texture and geometry information are concentrated in the $U$ and $V^{T}$. The singular value of $\Sigma$ represents the energy information of the image.

If $\Sigma_{2}$ is small enough, $L^{\prime}=U_{1} \Sigma_{1} V_{1}^{T}$ is the best $d$ rank approximation of $M$, namely,

$$
\left\|A-L^{\prime}\right\|=\min _{\operatorname{rank}(X)=d}\|A-L\| .
$$

$U$ can be regarded as its theme matrix, and singular value $\Sigma$ determines the importance of these themes. The smaller singular values reflect unimportant or subject to "noise" affected theme. Therefore the best low-rank approximation of $M$ is to get rid of these secondary themes. When $\Sigma_{2}$ is small enough, $d=\operatorname{rank}\left(\Sigma_{1}\right)$ is the number of important topics of $M . U_{1} \Sigma_{1} V_{1}^{T}$ is the best low-rank decomposition for $M$.

\subsection{On Angle Between Two Column Subspace}

Let:

$$
U_{U A}:=U_{A}, V_{U B}=U_{B}
$$

Let also $U_{U A}=\left[u_{1} u_{2} \cdots u_{p}\right]$ and $V_{U B}=\left[v_{1} v_{2} \cdots v_{q}\right]$. Angle between $A$ and $B$ can be calculated :

$$
M=\left[U_{U A}^{T} V_{U B}\right]
$$




$$
\cos ^{2}(\theta)=\operatorname{det}\left(M * M^{T}\right)
$$

\subsection{On Angle Between Two Row Subspaces}

Let:

$$
U_{V A}:=V_{A}, V_{V B}=V_{B}
$$

Let also $U_{V A}=\left[u_{1} u_{2} \cdots u_{p}\right]$ and $V_{V B}=\left[v_{1} v_{2} \cdots v_{q}\right]$. Angle between $U_{V A}$ and $V_{V B}$ can be calculated :

$$
\begin{aligned}
M & =\left[U_{V A}^{T} V_{V B}\right] \\
\cos ^{2}(\phi) & =\operatorname{det}\left(M * M^{T}\right)
\end{aligned}
$$

\subsection{Pair of Angles Between Two Images}

- Angle $\theta$ called left angle (column) between two matrices and angle $\phi$ called right angle (row) between two matrices. Furthermore, pair $(\theta, \phi)$, were called the pair of angles between two matrices

- From SVD factorization of matrices A and B, we can get a singular value of $d_{A}=$ diag $\left(D_{A}\right)$ and $d_{B}=\operatorname{diag}\left(D_{B}\right)$. Both values are used to calculate the distance between the two matrices, i.e $\rho(A, B)=\left\|d_{A}-d_{B}\right\|$, with $\|$.$\| is Euclidean distance from a vector.$

\section{Computing Pair of Angles Between Two Images}

An image of size $m \times n$ pixel can be seen as a matrix, hence we may be able to compute pair of angles between two images of the same size.

\section{Example 1.}

Here is an example of a matrix which is a representation of a black-and-white image.

Theta $=1.1921 \mathrm{e}-07$

$\operatorname{Phi}=0.66133$

In the appendix of [3], GNU-OCTAVE script to compute the pair of angles $(\theta, \phi)$ between two matrices was given, which is easily to modify for the case of images.

\section{Example 2.}

In the following example, a color image is used. The color image consists of 3 layers, respectively the Red, Green and Blue layers. Measured angle between pairs of pairs of layers of IPB color photo images. 

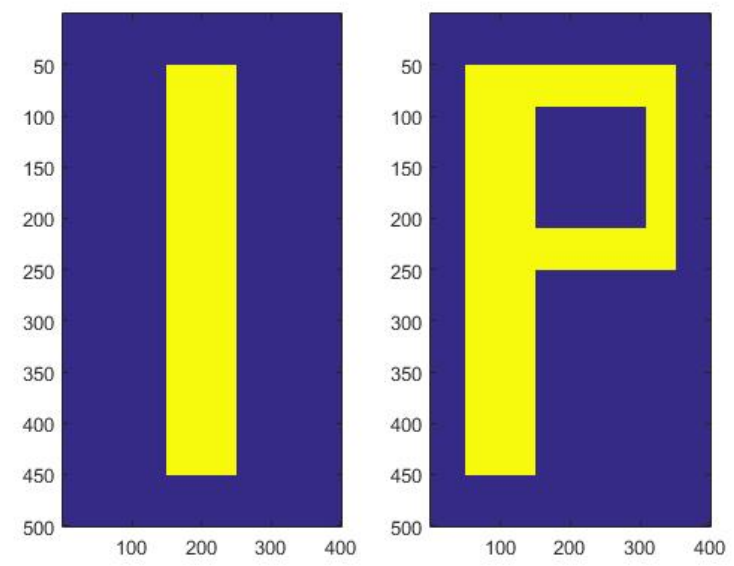

(a) Result 1

Figure 1. Example1.

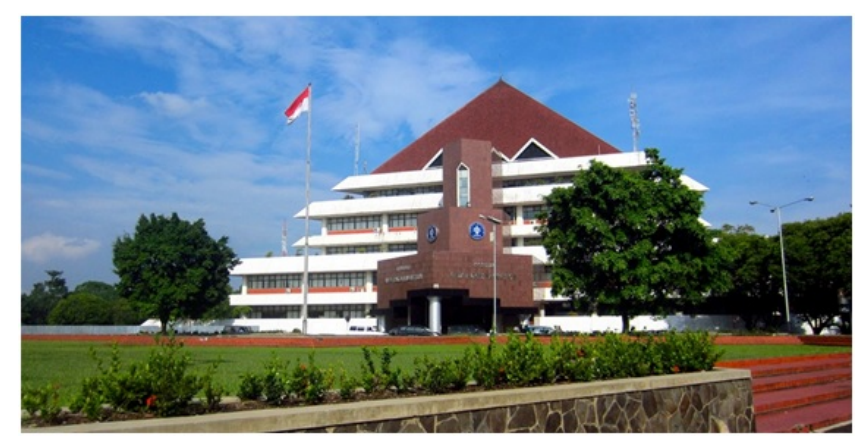

(b) Result 1

Figure 2. Example2.

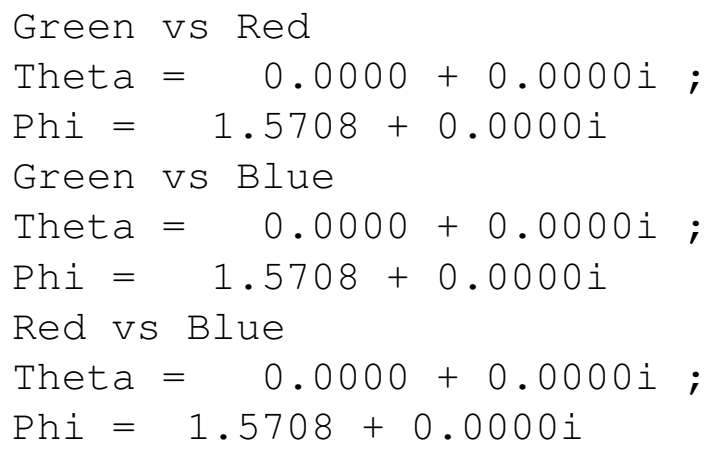

\section{CONCLUSIONS AND FUTURE RESEARCH DIRECTION}

This paper shows how to calculate a pair of angles between two images of the same size, using angles formula between two subspace. Another result that can be obtained is how to calculate the distance between two images of the same size for free.

The similarity angle (or cosine similarity) is used as a way to measure the similarity of two information vectors. Then, the angular pair $(\theta, \phi)$, becomes the double angle of similarity 
(cosine double similarity, bi-cosine similarity) of the two images. To be precise, the angle $\theta$ denoting angle of separation between theme subspace of the two figures, while the angle $\phi$ denoting angle of separation of geometric subspace between the two figures.

\section{REFERENCES}

[1] Antonellis, I., Gallopoulos, E., Exploring Term-Document Matrices from Matrix Models in Text Mining. Greece: University of Patras, 2006

[2] Berry, M.W., Browne, M., Understanding Search Engines: Mathematical Modelling and Text Retrieval. Philadelphia: Society for Industrial and Applied Mathematics, 1992

[3] Garnadi, A.D., 2019, Jarak dan Sudut antara Dua Matriks yang Berdimensi Sama, Jurnal Matematika Integratif, V15 No 1, pp??-?? akan terbit

[4] Gunawan, H., Neswan, O., On Angles Between Subspaces Of Inner Product Spaces. Vol. 11, No. 2. Indonesia: Math. Society (MIHMI), 2005

[5] Gunawan, H., Neswan, O., Setya-Budhi W. "A Formula for Angles Between Two Subspaces of Inner Product Spaces”, Beiträge Algebra Geom. Vol. 46(2), 311-320, 2005

[6] Leon, S.J., Aljabar Linear dan Aplikasinya. Edisi ke-5. A. Bondan, Penerjemah; Erlangga. Terjemahan dari Linear Algebra with Applications, 1998

[7] Rosliyanti, P.P., Alban, M., Agustian, R., Penerapan Konsep Dasar Aljabar Linear Untuk Menduga Terjadinya Plagiarisme. Makalah PKMI. Dir.Penelitian dan Pengabdian kepada Masyarakat, Depdiknas. Bogor: IPB, 2006

[8] Lestari, P.D. R., Agustian, R, Gafriadi,R., Febriyanti,A., dan Garnadi, A.D., Model Vektor dan Matriks dari Dokumen Serta Sudut antara Dua Vektor dan Dua Subruang untuk Menduga Dini Plagiarisme Dokumen, Manuskrip, https://dx.doi.org/10.31227/osf.io/hmntg

[9] Z. Y. Zhang and H. Q. Ye, "A divide-and-conquer algorithm for the rank-constrained subset selection problem," Mathematica Numerica Sinica, vol. 24, no. 2, pp. 229-242, 2002 .

[10] Li, Jinjiang and Li, Mengjun and Fan, Hui,Image inpainting algorithm based on low-rank approximation and texture direction, 2014, Mathematical Problems in Engineering 